\title{
A numerical investigation of natural convection heat transfer of copper-water nanofluids in a rectotrapezoidal enclosure heated uniformly from the bottom wall
}

\author{
Shantanu Dutta ${ }^{1 *}$, Arup Kumar Biswas ${ }^{2}$ \\ ${ }^{1}$ Department of Mechanical Engineering, NSHM Durgapur, West Bengal, Pin 713212, India \\ ${ }^{2}$ Department of Mechanical Engineering, NIT Durgapur, West Bengal, Pin 713209, India
}

Corresponding Author Email: shantanu.dutta@nshm.com

https://doi.org/10.18280/mmep.060114

Received: 11 October 2018

Accepted: 28 February 2019

\section{Keywords:}

natural convection, nanofluids,

\begin{abstract}
The present article numerically investigates the effects of natural convection of $\mathrm{Cu}$-water nanofluid in a two-dimensional rectotrapezoidal enclosure used in application of absorber plate fin. The inclination angle of rectotrapezoidal enclosure, region $\phi$ is chosen as $60^{\circ}$.The left and right vertical walls of the enclosure are maintained at a local cold temperature $\mathrm{T}_{\mathrm{c}}$ (heat sink) while the bottom wall is kept at a high temperature of $\mathrm{T}_{\mathrm{h}}$, respectively. The top wall of the enclosure is adiabatic. After non-dimensionalising the necessary governing controlling equations, the finite element strategy is adopted for solving the same. We present here the results in form of stream line contour, isotherm contours, local and average heat transfer rate $(\overline{N u})$ adopting a specific gamut of Rayleigh numbers i.e $10^{3} \leq \mathrm{Ra} \leq 10^{6}$. The solid volume fraction range of $\mathrm{Cu}$-water nanoparticles adopted for the present study is $(0 \leq \varphi \leq 0.1)$. The Prandtl number of the numerical simulation is maintained at 6.2.From the results it is observed that the higher stream line intensity is reported at a higher Rayleigh number for higher values of $\varphi$ and also it is found that with an increase of solid volume fraction $\varphi$, of copper water nanoparticles, average heat transfer rate $(\overline{N u})$ enhancement occurs. Accordingly, heat transfer enhancement greater than $20 \%$ as observed for higher $\mathrm{Ra}=10^{6}$, whereas $30 \%$ heat transfer enhancements are reported using $\mathrm{Cu}$-water nanofluid with $\mathrm{Ra}=10^{3}$.
\end{abstract}

\section{INTRODUCTION}

The subject, heat transfer and fluid flow in the presence of natural convection with or without the presence of nanofluid in different enclosures like square [1-3], enclosure with conducting solid square cylinder at center [4], rectangular [5], trapezoidal [6], quadrantal [7-8] has been extensively analysed in the last few decades using experimental and numerical procedure, as because it has been of considerable interest and has wide spread applications in many engineering applications, such as heat exchangers, energy efficient window designing, air conditioning of domestic and commercial buildings, crystal growth, solar water heaters and coolers, printed circuit board cooling, ocean engineering circulation etc. In this context, it goes without saying that when natural convection heat transfer is the primary source of heat transfer in complex enclosures, such systems needs to deeply understood for its thermal efficiency and other heat transfer parameters for bringing in more savings.

The subject nanotechnology, on the other hand is a multidisciplinary subject and is considered by many researchers to deeply understand more about material science, medical devices, thin film coatings, VLSI and solid state technology to name a few. It represents the most relevant leading-edge technology or state-of-the-art technology employed and being explored because its has a significant influence in the level of molecular dynamics with the ultimate aim for commercial success too. It is also harnessed in medical technology, MEMS technology, microfluidics and chemical technology. In the last few decades natural convection heat transfer researchers have tried to establish their findings by using conventional fluids like water or synthetic organic fluids in their study which are not as effective and are not having enhanced heat transfer parameters. However in the last decade on the other hand, there has been a growing demand for improvement of heat transfer efficiency worldwide because this involves energy saving and helps to prolong the working life of heat transfer equipment. Harnessing the power of larger thermal conductivity and larger convective heat transfer values, nanofluids proved to be an excellent alternative for conventional base fluids for improving of heat transfer which was achieved by suspending very small particles (in the range of $10^{-10} \mathrm{~m}$ ) in conventional fluids with or without the aid of surfactant. Nanofluids not only show promise in innovation and faster development of industrial heat transfer devices by significantly enhancing properties such as thermal transfer rates in a variety of applications, but it tries to guarantee that with minimum pressure drop. Choi [9] along with another researcher first introduced the term nanofluid, where they tried to suspend various metallic oxides in conventional fluid and coined the name nanofluids. Further nanofluids are considered to be a stable fluid with uniform distribution in the base fluid. In this context, it is important to note that nanofluids containing dispersed metal nanoparticles like copper in water can be produced physically in lab too by a 
'direct evaporation' technique. The presence of uniformly distributed nanoparticles is crucial and has a significant role in modifying the thermal conductivity of their corresponding base fluids. Quite a significant representation of literature based on experimental and numerical analysis has been carried out involving mechanisms of enhanced heat transfer of the nanofluids. Zi-Tao $\mathrm{Yu}$ et al. [10] reviewed the representation about steady natural convection of nanofluids in closed regions (square and rectangular enclosures, horizontal concentric ring passages and triangular enclosures), for a large range of unification and amalgamation of base fluids and nanoparticles. Khanafer et al. [11] adopted a numerical strategy and analysed the heat transfer performance in a two-dimensional rectangular enclosure exploiting the power of nanofluids by adopting a finite volume strategy. Jou and Tzeng [12] also used nanofluids for heat transfer enhancements utilising the effects of solid particle dispersion theory via natural convection method in a rectangular enclosure. They harnessed the numerical modelling of Khanafer's. The results by them indicated, that increase of volume fraction of nanofluids and buoyancy parameters caused an augmentation in the average heat transfer coefficient. Choi [13] also reported in another article about enhancements of heat transfer for $\mathrm{Cu}$-ethylene glycol nanofluids of $10 \mathrm{~nm}$ nanoparticle diameter, and clearly demonstrated the fact that, by using a $0.3 \%$ solid volume fraction had led to heat transfer enhancement of nearly $40 \%$.This was again explained by the author Choi [14] in an another research paper, where he reported that such properties could happen because of several characteristics like nanoparticle agglomeration and clustering [14], gravity energy conveyance [14], constitution of liquid/solid molecular interface formation [14], the interactive and impact among different nanoparticles leading to an augmentation of surface area. This nanoparticle intensification in the base fluid helped in increase of effective surface area of the nano fluid and further helped in multiplication of specific heat and thermal capacity, which was indeed what the heat transfer technologists were looking for in the long run. Generally its found that micro and nano topography could be built onto a surface subjected to heat transfer. Further nanoparticles considered for practical application includes a size of 1-100 $\mathrm{nm}$ and are generally made up of three layers namely surface shell and core and because of the presence of high surface area, the corresponding heat transfer enhancement is reported on the sub-surface of a nanoparticle, so this quality automatically takes care of augmentation of heat transfer via conduction heat transfer. In recent times Mahmoudi et al. [15] did a numerical investigation in a trapezoidal enclosure saturated by $\mathrm{Cu}$-water in the presence of a uniform magnetic field by control volume approach. They also enumerated the study of entropy generation inside the trapezoidal enclosure and reported the enhancement of heat transfer at higher Rayleigh numbers of $\mathrm{Ra}=10^{4}$ and $10^{5}$ due to presence of saturated $\mathrm{Cu}$-nanoparticles. They also reported that magnetic field's presence in the enclosure (enumerated via Hartmann number) resulted in a decrease of heat transfer even at higher Rayleigh numbers. Saleh et al. [16] also investigated a natural convection study based on finite difference strategy numerical approach, coupled with stream vorticity framework on different nanofluids like $\mathrm{Cu}$-water, $\mathrm{Al}_{2} \mathrm{O}_{3-}$ water inside a trapezoidal enclosure. The parameters that were investigated in detail in that paper was flow characteristics, heat transfer and rate of heat transfer on (i)
Grashof number (ii) Inclination angle of vertical trapezoidal enclosure walls (iii) nanoparticle volume fraction. They concluded their study by enumerating the fact that by choosing an acute inclination angle of trapezoidal enclosure with a high volume fraction of $\mathrm{Cu}$-water nanoparticle resulted in higher heat transfer rate. Esfe et al. [17] investigated a finite volume numerical study inside a trapezoidal enclosure filled with carbon nanotube and water based nanofluid. The relevant parameters taken up for discussion in their following paper was (i) different aspect ratios of trapezoidal enclosure (ii) nanoparticle volume fraction (iii) different range of Rayleigh numbers. They concluded their discussion by enumerating the fact that at lesser Rayleigh number $\left(\mathrm{Ra} \leqslant 10^{4}\right)$, the average heat transfer rate $(\overline{N u})$ showed a decreasing trend with an increase in aspect ratio of the trapezoidal enclosure at all solid volume percentage of carbon nanotube particles selected for the numerical study. Very recently Nayak et al. [18] carried out a numerical analysis with the presence of nanoparticles on the mixed convection of a $\mathrm{Cu}$-water nanofluid. The authors results demonstrated the fact, that the thermophoresis and Brownian diffusion parameter does not have a significant effect on most of parameter values selected for the mixed convection study. Also, Sharma et al. [19] recently carried out a study on unsteady electrically conducting nanofluid (alumina-sodium alginate nanofluid) coupled with MHD effect.

When the enclosure under investigation becomes irregular or complex in shape then there exists complicated interplay in between nanoparticle interaction with the enclosure boundaries. The presence of inclined boundaries of the rectotrapezoidal enclosure make the fluid flow and heat transfer effects more complex. Rectotrapezoidal geometry find many engineering utilizations in engineering fields such as electronic printed circuit board constituents, absorber plate fin, building insulation and complicated designed thermo liquid carriers. Recently Dutta and Biswas [20] have carried out a numerical investigation byharnessing mixed convection phenomenon, to scrutinize the transport mechanism of a liddriven rectotrapezoidal enclosure for heat transfer effects. The results showed that inclusion of $\mathrm{Cu}$-water nano-particles into thebase fluid had brought forward an enhancement of the heat transfer coefficient, which escalates with an enhancement of nano-particles volume concentration and Reynolds number ( $\mathrm{Re})$. With motivation obtained from the previous studies, the purpose of our new present investigation is to carry out a finite element based numerical analysis on natural convection in a rectotrapezoidal enclosure saturated with $\mathrm{Cu}$-water nanofluid. Two opposite sloping boundaries of the rectotrapezoidal cavity are kept at cold temperature and the bottom wall is maintained at high temperatures by a constant oil bath. The angle of the inlined sloping wall in the rectotrapezoidal enclosure is maintained at $\phi=60^{\circ}$. We adopt a finite element strategy to solve for the non-dimensional controlling mass momentum and energy equations. The presence of relevant parameters like Rayleigh number $\left(10^{3} \leq\right.$ $\left.\mathrm{Ra} \leq 10^{6}\right)$, and solid volume fraction $(0 \leq \phi \leq 0.1)$ on the flow and heat transfer inside the rectotrapezoidal enclosure are thoroughly discussed after assuming a fixed Prandtl number for the numerical study $(\operatorname{Pr}=6.2)$. As per author's belief numerical investigation in this geometry with nanofluid induced by natural convection has not been done. 


\section{MATHEMATICAL FORMULATION}

\subsection{Problem description}

Figure 1 depicts a simplified two -dimensional figure of the rectotrapezoidal enclosure, which is uniformly heated $\left(\theta=T_{h}\right)$ from the bottom. The upright walls and the inclined walls are kept at cold temperature $\left(\theta=T_{c}\right)$ while the top wall is insulated from surroundings. The initial temperature of the enclosure is maintained at the cold temperature $T_{c}$. The incination angle of rectotrapezoidal enclosure, $\phi$ is chosen as $60^{\circ}$. The fluid inside the enclosed area is a Cu-water based nanofluid.

The mathematical equations of the nanofluid enumerated in this article are described after taking into account:

- The fundamental basic fluid is water together with the $\mathrm{Cu}$-nanoparticles which are expected to be in thermal balance as a single constituent mixture.

- The nanofluid is a Newtonian fluid and incompressible and non-porous with no magnetic influence.

- The Cu-nanoparticles are generally assumed to be, spherical in nature.

- The Cu-nanofluid is considered to be stable and laminar.

- The presence of Brownian diffusion parameters and thermophoretic diffusion parameters are neglected in this present study.

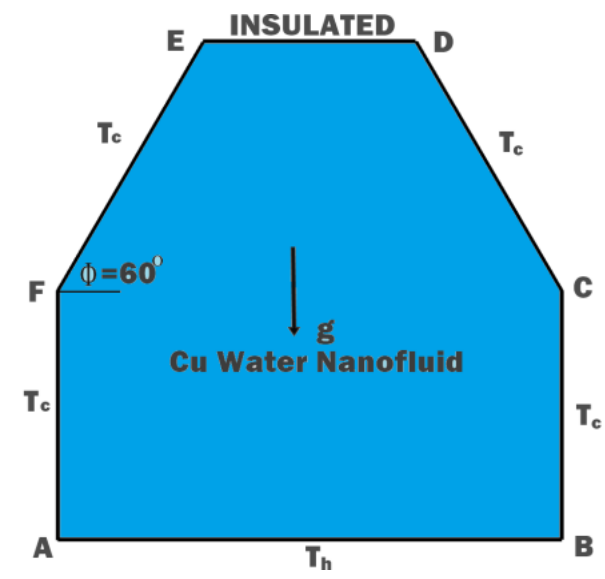

Figure 1. Representational diagram of the physical model

\subsection{Mathematical description of the physical model}

\subsubsection{Dimensional nature of equations}

The controlling mathematical statements for the rectotrapezoidal enclosure numerical study under investigation are dependent on the mass law balance, linear momentum balance, and thermal energy balance in steadfast conditions considering this to be a time independent problem formulation. Adopting into reckoning the assumptions from the previous section, the fundamental system of dimensional equations is enumerated below.

Mass law balance equation:

$\frac{\partial u}{\partial x}+\frac{\partial v}{\partial y}=0$

Which describe the velocities (u,v) according in the cartesian coordinate $\mathrm{x}$ and $\mathrm{y}$, respectively.

The linear momentum balance equation in $\mathrm{x}$ direction $u \frac{\partial u}{\partial x}+v \frac{\partial u}{\partial y}=\frac{1}{\rho_{n f}}\left[-\frac{\partial p}{\partial x}+\mu_{n f}\left(\frac{\partial^{2} u}{\partial x^{2}}+\frac{\partial^{2} u}{\partial y^{2}}\right)\right]$

where $\rho_{\mathrm{nf}}, \mathrm{p}$, and $\mu_{\mathrm{nf}}$ are the density of nanofluid, fluid pressure, and operative dynamic viscocity of the nanofluid for this numerical study, respectively.

The linear momentum balance equation in y direction is given by:

$u \frac{\partial v}{\partial x}+v \frac{\partial v}{\partial y}=\frac{1}{\rho_{n f}}\left[-\frac{\partial p}{\partial y}+\mu_{n f}\left(\frac{\partial^{2} v}{\partial x^{2}}+\frac{\partial^{2} v}{\partial y^{2}}\right)+(\rho \beta)_{n f} g\left(T-T_{c}\right)\right]$

where $\beta_{\mathrm{nf}}$ is the thermal expansion factor of the $\mathrm{Cu}$-water nanofluid, $T_{c}$ is the temperature of the upright and inclined walls.

The energy balance equation is given by:

$$
u \frac{\partial T}{\partial x}+v \frac{\partial T}{\partial y}=\alpha_{n f}\left(\frac{\partial^{2} T}{\partial x^{2}}+\frac{\partial^{2} T}{\partial y^{2}}\right)
$$

where $\alpha_{\mathrm{nf}}$ is the thermal diffusivity of $\mathrm{Cu}$-water nanofluid. We adopt the well known scholastic modelling enumerated in literature to resolve the characteristics of the $\mathrm{Cu}$-water nanofluid [17]:

$$
\begin{aligned}
& \rho_{n f}=(1-\phi) \rho_{f_{w}}+\phi \rho_{p_{n}} \\
& \left(\rho C_{p}\right)_{n f}=(1-\phi)\left(\rho C_{p}\right)_{f w}+\phi\left(\rho C_{p}\right)_{p_{n}} \\
& (\rho \beta)_{n f}=(1-\phi)(\rho \beta)_{f_{w}}+\phi(\rho \beta)_{p n} \\
& \alpha_{n f}=\frac{k_{n f}}{\left(\rho C_{p_{n}}\right)_{n f}}
\end{aligned}
$$

In the above mathematical equations, we assign the solid volume fraction parmeter to be $\varphi . \mathrm{C}_{\mathrm{pf}}, \rho_{n f}$ and $\mathrm{C}_{\mathrm{p} \text { nf }}$ are considered to be the specific heat of the base fluid, density and corresponding specific heat of $\mathrm{Cu}$-water nanofluid, respectively, and $\mathrm{k}_{\mathrm{n}}$ is the effective thermal conductivity of nanoparticle. It is to noted that equations (5-8) takes into account the subscripts $f_{w}$ and $p_{n}$ which denote water (base fluid) and $\mathrm{Cu}$-nanoparticle, respectively. The numerically modelled dynamic viscocity and thermal conductivity parameters are adopted from the published literature [refer Xuan, Wen and Brinkman [21, 22, 23]].

$$
\begin{aligned}
& \mu_{n f}=\frac{\mu_{f_{w}}}{(1-\phi)^{2.5}} \\
& k_{n f}=k_{f_{w}}\left[\frac{\left(k_{p_{n}}+2 k_{f_{w}}\right)-2 \phi\left(k_{f_{w}}-k_{p_{n}}\right)}{\left(k_{p_{n}}+2 k_{f w}\right)+\phi\left(k_{f_{w}}-k_{p_{n}}\right)}\right]
\end{aligned}
$$

\subsubsection{Non-dimensional form of equations}

To represent various transport mechanisms in nanofluids, it is essential and worthwhile for the conservation equations to be in non-dimensional form. So we introduce the following non-dimensionless parameters: 
$X=\frac{x}{L}, Y=\frac{y}{L}, U=\frac{u L}{\alpha_{f}}, V=\frac{v L}{\alpha_{f}}, \quad \theta=\frac{T-T_{c}}{T_{h}-T_{c}}, P=\frac{p L^{2}}{\rho_{n f} \alpha_{f}{ }^{2}}$,

$\operatorname{Pr}=\frac{v_{f}}{\alpha_{f}}, R a=\frac{g \beta_{f} L^{3}\left(T_{h}-T_{c}\right)}{v_{f} \alpha_{f}}$

This parameter $\mathrm{L}$, is the physical $\mathrm{x}$ dimension for this rectotrapezoidal enclosure considered, $U$ and $V$ are the dimensionless velocity components in horizontal and vertical orientations in conjunction. $\alpha_{\mathrm{f}}$ is the thermal diffusivity of base fluid (water), $\theta$ is non-dimension temperature, $P$ is the dimensionless pressure, $\rho_{n f}$ is the density of $\mathrm{Cu}$-water nanofluid, $v_{\mathrm{f}}$ is kinematic viscosity of base fluid, $\beta_{\mathrm{f}}$ is volumetric thermal expansion coefficient of base fluid (water) and $\mathrm{g}$ is the acceleration due to gravity.

After introducing these non-dimensional parameters in the controlling mathematical equations we further re-represent the continuity, momentum, and energy equations as belowMass law balance equation:

$\frac{\partial U}{\partial X}+\frac{\partial V}{\partial Y}=0$

Linear momentum conservation in $\mathrm{X}$ and $\mathrm{Y}$ direction is given by:

$U \frac{\partial U}{\partial X}+V \frac{\partial V}{\partial Y}=-\frac{\partial P}{\partial X}+\left(\frac{\mu_{n f}}{\alpha_{n f} \alpha_{f w}}\right)\left(\frac{\partial^{2} U}{\partial X^{2}}+\frac{\partial^{2} U}{\partial Y^{2}}\right)$

$U \frac{\partial V}{\partial X}+V \frac{\partial V}{\partial Y}=-\frac{\partial P}{\partial Y}+\left(\frac{\mu_{n f}}{\alpha_{n f} \alpha_{f_{w}}}\right)\left(\frac{\partial^{2} V}{\partial X^{2}}+\frac{\partial^{2} V}{\partial Y^{2}}\right)+\frac{(\rho \beta)_{n f}}{\rho_{n f} \beta_{f_{w}}} R a \operatorname{Pr} \theta$

Energy equation

$U \frac{\partial \theta}{\partial X}+V \frac{\partial \theta}{\partial Y}=\frac{\alpha_{n f}}{\alpha_{f_{w}}}\left(\frac{\partial^{2} \theta}{\partial X^{2}}+\frac{\partial^{2} \theta}{\partial Y^{2}}\right)$

The following boundary conditions below are adopted in this rectotrpaezoidal enclosure to solve Eqs. (11)-(14):

$$
\begin{aligned}
& \mathrm{U}(\mathrm{X}, 0)=\mathrm{U}(\mathrm{X}, 1)=\mathrm{U}(0, \mathrm{Y})=\mathrm{U}(1, \mathrm{Y})=0 \\
& \mathrm{~V}(\mathrm{X}, 0)=\mathrm{V}(\mathrm{X}, 1)=\mathrm{V}(0, \mathrm{Y})=\mathrm{V}(1, \mathrm{Y})=0 \\
& \theta(0, \mathrm{Y})=\theta(1, \mathrm{Y})=0
\end{aligned}
$$

Eq. (15 (b)) is valid along walls BC, CD, EF and AF)

$\theta(\mathrm{X}, 0)=1$

Eq. (15 (c)) is valid along wall AB

$\frac{\partial \theta}{\partial \mathrm{Y}}(\mathrm{X}, 1)=0$

Eq. (15 (d)) is valid along wall DE

\subsubsection{Nusselt number calculation}

The local heat transfer rates on the boundary walls of the rectotrapezoidal enclosure can be defined in terms of local
Nusselt number (non-dimensional number). They are numerically evaluated along the heated/cold wall(s) of the $\mathrm{RT}$ enclosure and are represented as enumerated below:

$N u=-\left(\frac{k_{n f}}{k_{f}}\right) \frac{\partial \theta}{\partial n}$

where $\frac{\partial}{\partial n}$ can be depicted as partial differentiation obtained accompanying the path of the exterior commensurate perpendicular normal of the recto trapezoidal wall under investigation being considered (hot or cold wall whichever the case may be).

Similarly the average heat transfer rates $(\overline{N u})$ for a wall of any length (say L) can also be calculated numerically:

$N u_{\text {avg }}=\frac{1}{L} \int_{0}^{L} N u_{l} d l$

\section{NUMERICAL SIMULATION TECHNIQUE ADOPTED}

For the present numerical scheme adopted in the present investigation, the resulting governing transport differential equations (Eqs.11-14) together with the boundary conditions presented in (Eqs. 15a-d) as discussed in section 2.2.2 are investigated by a finite element solver technique. Further we adopt the well known Galerkin weighted residue finite element scheme to take care of the controlling mathematical non-linear partial differential equations. Further this same Galerkin weighted method is also adopted and solved to transform the non-linear governing equations as discussed earlier to form an organised set of fundamental constituent mathematical equations. The comprehensive description of this finite element strategy can be found in the book by Zienkiewicz [24]. The Gauss's quadrature method as discussed in Zienkiewicz [24] is used to perform the numerical integration. The Newton-Raphson numerical analysis method is adopted to account for the consideration of the algebraic equations set. The convergence criterion is analysed in such an aspect that $\left|\varphi_{t}{ }^{n+1}-\varphi_{t}{ }^{n}\right| /\left|\varphi_{t}{ }^{n}\right| \leq 10^{-6}$ where $\phi_{\mathrm{t}}$ represents any transport variable. After the non linear equations are solved, the displayed results are depicted via isotherm contour and stream line contour $(\psi)$ which are having a direct relationship with the $\mathrm{X}, \mathrm{Y}$ directions velocity components $(\mathrm{U}, \mathrm{V})$. Further the relevance between the stream line contour and the cartesian coordinate velocities ( $\mathrm{U} \& \mathrm{~V})$ are $U=\frac{\partial \psi}{\partial Y}$ and $V=-\frac{\partial \psi}{\partial X}$ which conclusively formulate to a solo poisson's mathematical equation is solved through Galerkin finite element method.

$\frac{\partial^{2} \psi}{\partial X^{2}}+\frac{\partial^{2} \psi}{\partial Y^{2}}=\frac{\partial U}{\partial Y}-\frac{\partial V}{\partial X}$

The symbol $\psi$ has a positive and negative connotation where positive sign of stream function denotes a counterclockwise flow circulation and vice versa. The thermophysical dominion of the base fluid [water $\left(\mathrm{H}_{2} \mathrm{O}\right)$ ] along with copper [23] $(\mathrm{Cu})$, are given in Table 1 . 
Table 1. Thermophysical dominion of water and nanoparticles

\begin{tabular}{|c|c|c|}
\hline Property & $\begin{array}{c}\text { Base fluid } \\
\text { (water) }\end{array}$ & $\begin{array}{c}\text { Nano } \\
\text { Particles }(\mathbf{C u})\end{array}$ \\
\hline Density $\left(\mathrm{Kg} / \mathrm{m}^{3}\right)$ & 997.1 & 8933 \\
\hline Specific heat $\mathrm{C}_{\mathrm{p}}(\mathrm{J} / \mathrm{kg} \mathrm{k})$ & 4179 & 385 \\
\hline $\begin{array}{c}\text { Thermal conductivity K }(\mathrm{W} / \mathrm{m} \\
\mathrm{k})\end{array}$ & 0.605 & 401 \\
\hline Dynamic viscosity $(\mathrm{kg} / \mathrm{ms})$ & $8.91 \times 10^{-5}$ & --- \\
\hline $\begin{array}{c}\text { Thermal expansion coefficient } \\
\left(\mathrm{k}^{-1}\right)\end{array}$ & $2.1 \times 10^{-4}$ & $1.67 \times 10^{-5}$ \\
\hline
\end{tabular}

\section{VALIDATION OF THE MODEL AND GRID INDEPENDENCY TEST}

\subsection{Validation}

The present numerical finite element strategy adopted by authors is taken up for validation, by comparing with the numerical experiments of (i) Oztop and Abu-Nada [5] (ii) Abu-Nada and Oztop [25].The validation comprises by comparing the present code average heat transfer rate $(\overline{N u}$ or

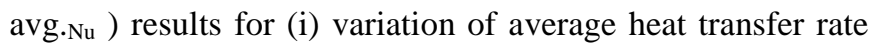
( $\overline{\mathrm{Nu}}$ )for three volume fraction (i.e $\varphi=0.05,0.1$ and 0.2 ) for different aspect ratio in an rectangular enclosure $(\mathrm{A}=0.5,1$ and 2) saturated with $\mathrm{Cu}$-water nanofluid at $\mathrm{Ra}=10^{5}$ and (ii) Average heat transfer rate $(\overline{N u})$ for $\mathrm{Ra}=10^{5}$ for volume fraction $\varphi=0.1$ for the inclination angle $\phi$ of $30^{\circ}$ and $60^{\circ}$ case saturated with $\mathrm{Cu}$-water nanofluid and as displayed in Table 2 (a \& b).

Table 2(a). Validation Table of avg.Nu $(\overline{N u})$ for present code (P.C) vs Oztop \& Abu-Nada paper [5] values for three different aspect ratios of $(\mathrm{A}=0.5,1$ and 2$)$ and three different volume fraction $\varphi=0.05,0.1$ and 0.2 at $\mathrm{Ra}=10^{5}$ for $\mathrm{Cu}$-water nanofluid

\begin{tabular}{|c|c|c|c|c|c|c|}
\hline $\boldsymbol{\varphi}$ & $\mathbf{A = 0 . 5}$ & P.C A=0.5 & $\mathbf{A = 1}$ & P.C A=1 & $\mathbf{A = 2}$ & P.C A=2 \\
\hline 0.05 & 3.87 & $3.69(4.8 \%)$ & 3.96 & $3.78(4.5 \%)$ & 4.16 & $3.97(4.5 \%)$ \\
\hline 0.1 & 4.15 & $3.99(3.8 \%)$ & 4.28 & $4.09(4.4 \%)$ & 4.75 & $4.55(4.2 \%)$ \\
\hline 0.2 & 4.56 & $4.34(4.8 \%)$ & 4.75 & $4.57(3.8 \%)$ & 5.35 & $5.20(2.8 \%)$ \\
\hline
\end{tabular}

Table 2(b). Validation Table of $\operatorname{Avg}_{\mathrm{Nu}}(\overline{N u})$ for present code vs. Abu-Nada \& Oztop paper [25] for three different Rayleigh numbers of $\left(\mathrm{Ra}=10^{3}, 10^{4}\right.$ and $\left.10^{5}\right)$ and for two orientations ( $\phi=30^{\circ}$ and $60^{\circ}$ ) and volume fraction $\varphi=0.1$ for $\mathrm{Cu}$-water nanofluid

\begin{tabular}{|c|c|c|c|c|}
\hline $\begin{array}{l}\text { Rayleigh } \\
\text { numbers }\end{array}$ & $\phi=30^{\circ}$ & $\begin{array}{c}\text { Present } \\
\text { code } \\
\phi=30^{\circ}\end{array}$ & $\phi=60^{\circ}$ & $\begin{array}{c}\text { Present } \\
\text { code } \\
\phi=60^{\circ}\end{array}$ \\
\hline $10^{3}$ & 1.56 & 1.49 & 1.53 & 1.48 \\
\hline $10^{4}$ & 3.18 & 3.05 & 3.09 & 3.08 \\
\hline $10^{5}$ & 6.25 & 5.99 & 5.90 & 5.95 \\
\hline
\end{tabular}

The validation results for the average heat transfer rate (avg.Nu) values as depicted in Table $2(a \& b)$ reveal that, the present finite element strategy is in good compliance with the previous researchers articles as reported. The variation of heat transfer rate $(\overline{N u})$ is less than $5 \%$ in all the above cases as discussed [ Note that the numerical values in bracket are the $\%$ change from the validation reference paper values].

\subsection{Grid independency}

The average heat transfer rate (avg. ${ }_{\mathrm{Nu}}$ or $\overline{N u}$ ) considering the lower hot horizontal boundary wall for rectotrapezoidal enclosure was numerically simulated for three different finite elements namely 31090, 44232 and 68790 at fixed volume fraction of $\varphi=0.1$ and is depicted in Table 3. It was found that there is less than $4 \%$ change of average Nusselt number $(\overline{\mathrm{Nu}})$ when we changed the finite elements from 44232 to 68790 and hence we proceed with 44232 finite elements. Further special care was taken to refine the grids at corners and edges because of finite discontinuity at edges.

Table 3. Average heat transfer rate, avg.Nu $(\overline{N u})$ on the hot bottom wall of rectotrapezoidal enclosure, according to different Rayleigh number saturated with $\mathrm{Cu}$-water nanofluid having $\varphi=0.1 \%$

\begin{tabular}{|c|c|c|c|}
\hline Ra & $\begin{array}{c}\mathbf{3 1 0 9 0} \\
\text { elements }\end{array}$ & $\begin{array}{c}\mathbf{4 4 2 3 2} \\
\text { elements }\end{array}$ & $\begin{array}{c}\mathbf{6 8 7 9 0} \\
\text { elements }\end{array}$ \\
\hline $10^{6}$ & 19.669 & 19.97 & 20.15 \\
\hline $10^{5}$ & 13.611 & 13.911 & 14.10 \\
\hline $10^{4}$ & 9.9798 & 10.279 & 10.557 \\
\hline $10^{3}$ & 9.626 & 9.9251 & 10.203 \\
\hline
\end{tabular}

\section{RESULTS AND DISCUSSIONS}

\subsection{Impact of vol. fraction on the stream line contours $(\psi)$ and isothermal contours $(\theta)$ considering different Rayleigh numbers}

The recto-trapezoidal enclosure under study is saturated with a $\mathrm{Cu}$-water nanofluid involving a concentrated solid particle volume fraction range of $0 \leq \varphi \leq 0.1$ for this numerical analysis. Figures 2 and 3 depicted below represent the streamline contour $(\psi)$ and isothermal contour $(\theta)$ for three Rayleigh number set $\left(\mathrm{Ra}=10^{4}, 10^{5}\right.$ and $\left.10^{6}\right)$ for solid particle volume fraction 0.05 and 0.1 respectively. The depicted figures discussed below also accounts for a representational distribution and illustrates the stream line contour $(\psi)$ and isotherm contour $(\theta)$ of nanofluid (black lines) and pure fluid(water) (blue lines) in unison.

For this article we have shown only the streamline contour values for the nanofluid and we have shown numerical values for both the water (base fluid) and nanofluid for the isotherms, though they seem to overlap in these cases for our numerical simulation results. The presence of $\mathrm{Cu}$-nano particles inside the enclosure influences the display pattern and numerical values of stream line contour $(\psi)$ and isothermal contour $(\theta)$. In figure $2(\mathrm{a})$, at lower $\mathrm{Ra}=10^{4}$ the presence of nanoparticles on the thermal boundary region next to the heated bottom wall of rectotrapezoidal enclosure is less influenced by the addition of nanoparticles but at higher $\mathrm{Ra}=10^{5}$ and $10^{6}$ as found in figure 2(b) and (c) respectively, the effects are more. In this context its also important to enumerate the fact that the behavior of heat transfer regime and dominant thermal boundary substratum to the solid volume fraction of nanoparticles is closely associated with the augmentation of thermal conductivity of the nanofluid. As we have induced uniform cooling on the upright and slanting walls of rectotrapezoidal enclosure the numerical simulation outcomes are a combination of anticlockwise and clockwise flow vortices occupying the left 
part and right part of rectotrapezoidal area for all the numerical parameters adopted for this study. Each rotating circulation roll ascends along the cold left upright walls meets the slanting walls of the trapezoidal portion along the central mid line axis, and finally hits the top insulated boundary wall through which it undertakes its horizontal/downright movement towards the right slanting cold boundaries and decisively cascade downwards under the effect of cooling. From the analysis in Figure (2) a-c its also found that streamline exhibit two equal rolls of clockwise and anticlockwise strength inside the enclosure because of symmetric nature of the enclosure shape for all Rayleigh numbers discussed. At lower Rayleigh number of $\mathrm{Ra}=10^{4}$ the stream line strength is of less magnitude $\left(\psi_{\max }=7.3\right.$ in anticlockwise direction and $\psi_{\min }=4.7$ in clockwise direction) (refer figure 2(a)). With increase of $\mathrm{Ra}=10^{5}$ (refer figure 2(b)) the stream line strength increases in magnitude $\left(\psi_{\max }=59.7\right.$ in anticlockwise direction and $\psi_{\min }=39.68$ in clockwise direction) means convection effects are dominant in the enclosure. With further increase of Ra to $10^{6}$ its found that convection effects are very much dominant with very high strength of stream line contour strength in enclosure $\left(\psi_{\max }=\right.$ 272 in anticlockwise direction and $\psi_{\min }=152$ in clockwise direction). Further the stream lines are also no longer smooth and round but exhibit elliptical shape (refer figure 2(c)). Also at $\mathrm{Ra}=10^{6} \psi_{\max }$ base fluid $=271, \psi_{\min }$ base fluid $=-149$ numerical values are obtained but not presented in the figures. Analysing Figure 3(a-c) it is found that the isotherms also exhibit larger twisting and maximum isotherm strength are also observed at bottom wall or near the junction of bottom and cold upright wall. This is further proved from the fact by analysing the isotherms, that they are no longer symmetric and elliptic but exhibit a lot of twisting as clearly visible from the center of enclosure as because the effects of advection are predominant and due to initiation of convection. As a consequence, at higher $\mathrm{Ra}=10^{5}$ and $10^{6}$, (refer figures $3(\mathrm{~b}$ and c)) the numerical value of temperature gradient near both the lower boundary wall and upside boundary walls of the rectotrapezoidal enclosure tend to be large mainly attributed to the multifarious synergy of $\mathrm{Cu}$-water nanofluid with these boundary walls leading to a formation of thermal boundary substratum. Also its important to state that the presence of larger circulation flow strength in the interior core of the rectotrapezoidal enclosure can be attributed to stagnation of flow as observed, because its far away from the heated wall.

Also at lower $\mathrm{Ra}=10^{4}$ its observed that heat transfer due to base fluid is more than that for the nanofluid but the effects are just the reverse where the presence of nanofluid at higher Rayleigh numbers results in higher heat transfer rate as its clear from isothermal and stream line contour patterns and stream vorticity values demonstrated in Figure 2(a-c).

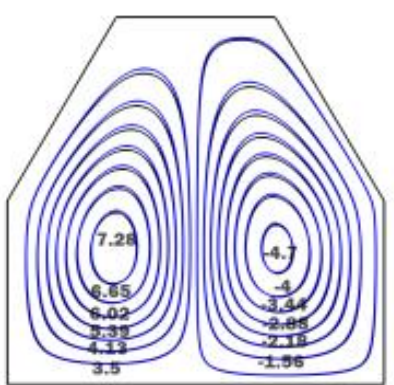

2(a)

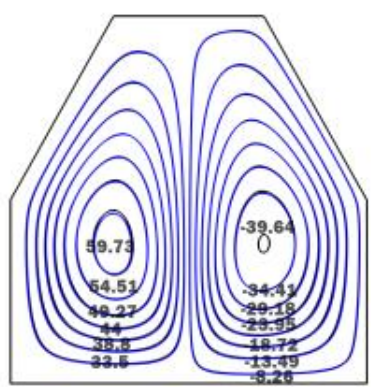

2(b)

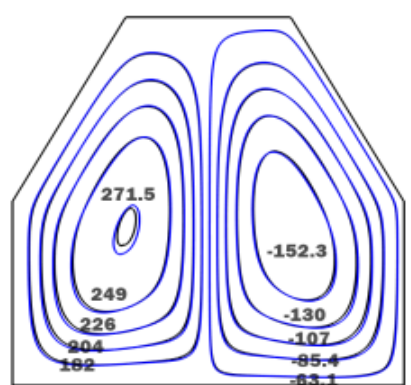

2(c)

Figure 2. Streamline contour $(\psi)$

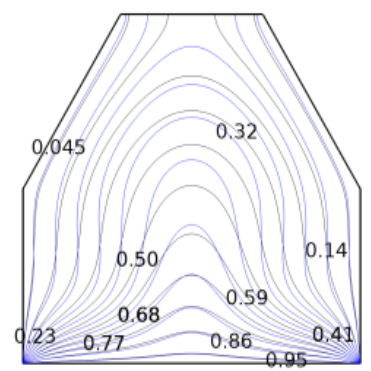

$3(\mathrm{a})$

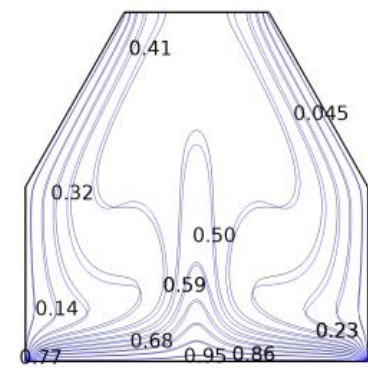

3(b)

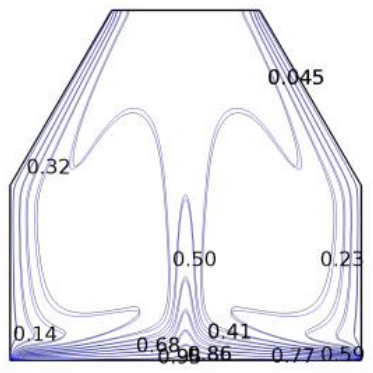

$3(\mathrm{c})$

Figure 3. Isothermal contour $(\theta)$ for volume fraction $\varphi=0.05$ (a) $\mathrm{Ra}=10^{4}$ (b) $\mathrm{Ra}=10^{5}$ (c) $\mathrm{Ra}=10^{6}$. [Note: The black line indicates nanofluid while the blue line indicates base fluid]

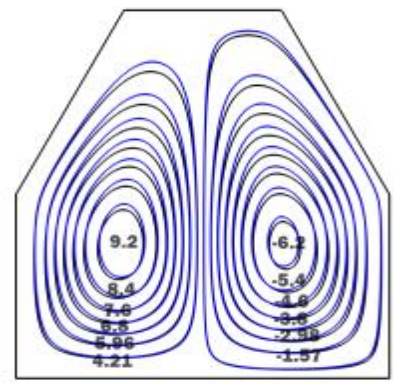

4(a)

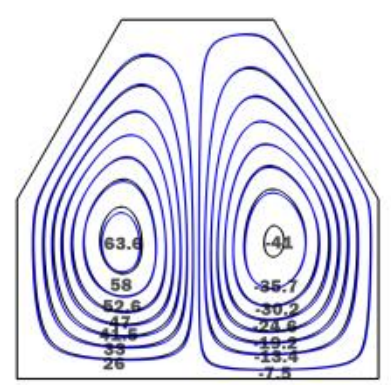

4(b)

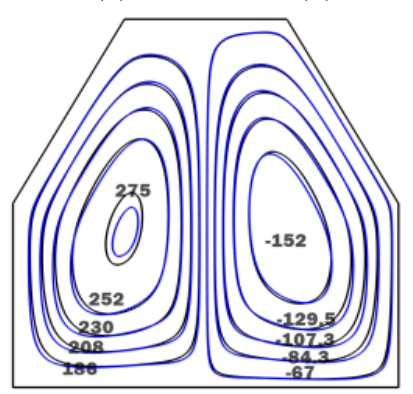

4(c)

Figure 4. Streamline contour $(\psi)$ 


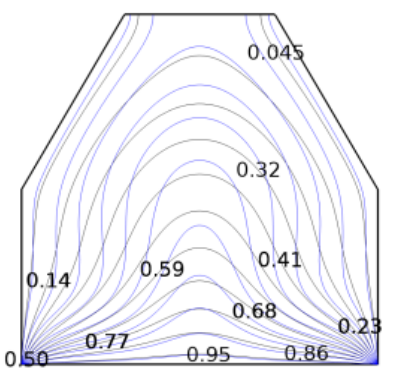

$5(a)$

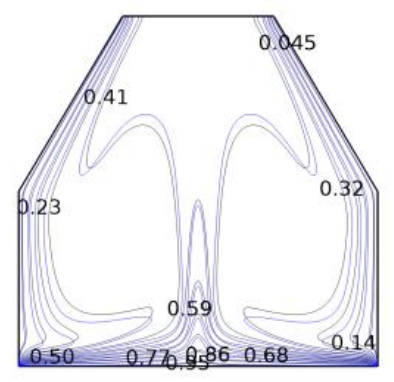

$5(\mathrm{c})$

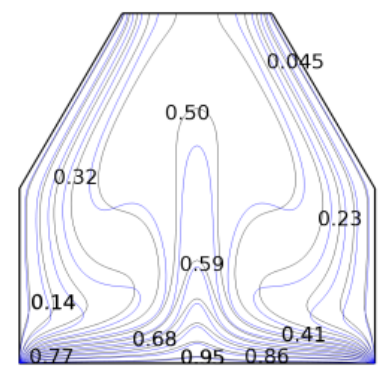

5 (b)
Figure 5. Isothermal contour $(\theta)$ for volume fraction $\varphi=0.1$ (a) $\mathrm{Ra}=10^{4}$ (b) $\mathrm{Ra}=10^{5}$ (c) $\mathrm{Ra}=10^{6}$ The black line indicates nanofluid while the blue line indicates base fluid

Analysing Figure 4 (a-c) we find that the qualitative nature of stream line and isotherm doesn't change much when we increase the solid particle fraction of nanofluid from $\varphi=0.05$ to 0.1 . However the velocity components of $\mathrm{Cu}$-water nanofluid increase with the intensification of solid particle percentage and further assists in an enhancement of the energy conveyance/transport in the fluid. Thus, the shape of central cell is no longer circular but becomes elliptical with an enhancement of solid particle volume fraction of nanofluid. The numerical values of stream line contour $(\psi)$ in these figures $4(a-c)$ demonstrate the fact that when we increase the nanoparticle volume fraction the flow strength also indicate an upward trend. The numerical value of stream line contour observed for $\mathrm{Ra}=10^{4}\left(\psi_{\max }=9.4\right.$ in anticlockwise direction and $\psi_{\min }=-6.2$ in clockwise direction) (refer figure 4(a)). With increase of $\mathrm{Ra}=10^{5}$ the stream line strength increases in magnitude $\left(\psi_{\max }=63.6\right.$ in anticlockwise direction and $\psi_{\min }=-41$ in clockwise direction) (refer figure 4(b)) and with further increase of $\mathrm{Ra}=10^{6}$ the stream line strength observed is $\left(\psi_{\max }=274\right.$ in anticlockwise direction and $\psi_{\min }=-$ 152 in clockwise direction). (Refer figure 4(c)).

Figure 5(a-c) displays the isothermal plots for $\mathrm{Ra}=10^{4}, 10^{5}$ and $10^{6}$ respectively and it is clearly observed that the qualitative nature is not much different for lesser volume fraction $\varphi=0.05$. (i.e figure $3(\mathrm{a}-\mathrm{c})$ ). But some quantitative differences are vivid from the figures.

\subsection{Analysis of local heat transfer rate ( $\mathrm{Nu})$ Vs. length for different Rayleigh numbers/different volume fraction}

In this section we plot different local Nusselt number to analyses the local heat transfer rate on different walls.

Figure $6 a-c$ depicts the graphical nature of local heat transfer rate (Nusselt number) Vs Dimensionless length (L) and for fixed $\operatorname{Pr}$ and fixed solid volume fraction $\varphi=0.1$ for different boundaries of rectotrapezoidal enclosure. Figure 6(a) demonstrates the heat transfer rate (local $\mathrm{Nu}$ ) at the bottom boundary wall. The enclosure as we have depicted for our numerical study is symmetrical about the cordinates $(X=0.5$, $\mathrm{Y}=0-1)$. The corresponding hear transfer rate at $\mathrm{X}=0.5$ is minimum for all Rayleigh number. Also due to the chosen boundary condition of bottom boundary wall, the local heat transfer rate $(\mathrm{Nu})$ shows a dip in value for all Rayleigh number as we proceed from left or right end boundary walls. Further the plots also reveal that the numerical values are maximum for $\mathrm{Ra}=10^{6}$ and its minimum for $\mathrm{Ra}=10^{3}$ as already it can be ascertained from the isotherm plots from the previous section. Figure $6 \mathrm{~b}$-c reveals the local heat transfer values $(\mathrm{Nu})$ at the cold vertical and slanting side walls of rectotrapezoidal enclosure. Due to presence of symmetry in rectotrapezoidal enclosure and due to the same boundary condition of cold walls, the local Nusselt number is nearly identical vs Y(Dimensionless length) but positive (although very less in magnitude) all along for both the LH and RH side walls excepting at the corners of the walls of enclosure ( here its infinitely high at the LH side of enclosure for the left wall and infinitely high at the $\mathrm{RH}$ side of enclosure for the right wall). This was already discussed above because of chosen boundary conditions and can be easily ascertained from the analysis of nature of isotherm contours from the previous section. The dense nature of temperature contours at the confluence of bottom boundary walls and cold upright walls result in large heat transfer rate in these zones. The local heat transfer $(\mathrm{Nu})$ also display a regular uniform pattern because of the heating strategy used.

Figure 7(a-c) displays local heat transfer $(\mathrm{Nu})$ for three different nanoparticle concentrations which are used as $\varphi=0$, 0.05 , and 0.1 and for a fixed $\mathrm{Ra}=10^{6}$.

The illustration reveals that the presence of $\mathrm{Cu}$ nanoparticles concentration which affects the local heat transfer $(\mathrm{Nu})$ such that it is less pronounced at low particle vol. fraction and the effect is more at larger vol. fraction. Further for upright and inclined side walls the heat transfer values show local dip in value at center Y (enclosure height, dimensionless) because of the inherent rectotrapezoidal geometry and shows further enhancement thereafter.

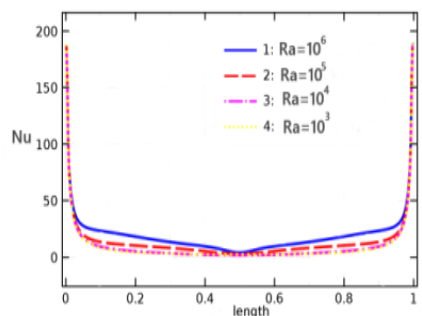

(a)

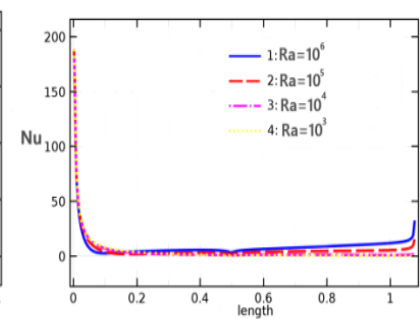

(b)

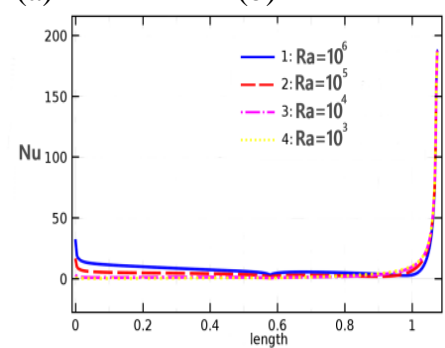

(c)

Figure 6. Local Nusselt number vs Length for different Ra with volume fraction $\varphi=0.1$ (a) Bottom wall (b) Left wall (c) Right wall 


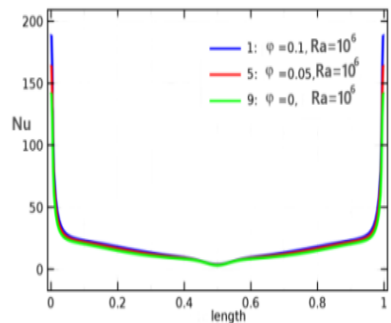

(a)

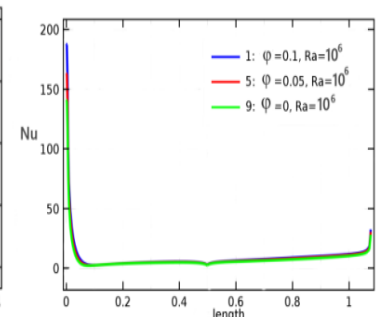

(b)

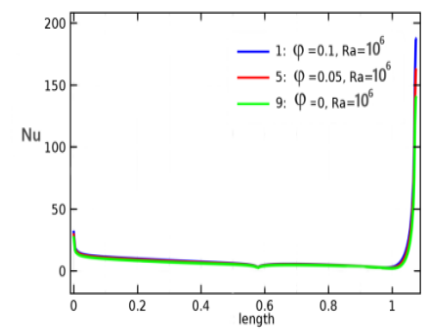

(c)

Figure 7. Local heat transfer rate $(\mathrm{Nu}) \mathrm{Vs}$. Length for three volume fraction $\varphi=0,0.05$ and 0.1 for $\mathrm{Ra}=10^{6}$. (a) Bottom wall (b) Left wall (c) Right wall

\subsection{Average Nusselt number $(\overline{N u})$ for different Rayleigh numbers and for different volume fraction}

This section below at different walls for different section. enumerates the average Nusselt number.

Table 4. Average Nusselt number (vs.) Ra for bottom wall and left cold wall for volume fraction $\varphi=0.05$

\begin{tabular}{|c|c|c|c|}
\hline SL no & Ra & Bottom wall & Left cold wall \\
\hline 1 & $10^{3}$ & 8.65 & 4.32 \\
\hline 2 & $10^{4}$ & 9.20 & 4.60 \\
\hline 3 & $10^{5}$ & 12.64 & 6.33 \\
\hline 4 & $10^{6}$ & 18.33 & 9.19 \\
\hline
\end{tabular}

Table 5. Average Nusselt number (vs.) Ra for bottom wall and left cold wall for volume fraction $\varphi=0.1$

\begin{tabular}{|c|c|c|c|}
\hline SL no & Ra & Bottom wall & Left cold wall \\
\hline 1 & $10^{3}$ & 9.93 & 4.96 \\
\hline 2 & $10^{4}$ & 10.28 & 5.14 \\
\hline 3 & $10^{5}$ & 13.92 & 6.97 \\
\hline 4 & $10^{6}$ & 19.97 & 10.02 \\
\hline
\end{tabular}

Table 4 exhibits the numerical results of average heat transfer rate $(\overline{N u})$ on the heated rectotrapezoidal bottom boundary and cold inclined and vertical boundary wall for different values of Rayleigh number and for chosen vol. fraction $\varphi=0.05$. It is important to discuss that for even for lower $R a=10^{3}$, the average heat transfer rate (avg. $\mathrm{Nu}$ or $(\overline{N u})$ ) as numerically evaluated on heated RT horizontal bottom and upright and inclined left wall (cumulated) is the least amongst all but still holds a high numerical value because of constant heating. Lesser value means, because at lesser Rayleigh number the heating mode of heat transfer is conduction. Further numerical value of average heat transfer rate as reported for Rayleigh number, $R a=10^{4}$ is nearly matching for lower $R a=10^{3}$ reiterating the fact that convection dominance is absent in the RT enclosure. Increasing the Rayleigh number further to $10^{5}$ and $10^{6}$ results show enhanced numerical values of average heat transfer rates clearly signifying convection is the dominant factor in the enclosure for this Rayleigh numbers.

Table 5 depicts the numerical simulation results of average heat transfer rate $(\overline{N u})$ of RT enclosure for hot horizontal bottom wall and cold upright and inclined walls for different values of Rayleigh number and for volume fraction $\varphi=$ 0.1 . The existence of enhanced vol. fraction of $\varphi=0.05$ to 0.1 outcome is, augmentation of heat transfer in the enclosure for all Rayleigh numbers discussed for this numerical study on both bottom and vertical left boundary walls. This is mainly attributed to that fact that as the solid particle concentration intensifies, the flow velocities at the middle zone of the rectotrapezoidal enclosure escalate as a result of higher solid-fluid interaction and results in conveyance of heat transfer. Thus it can be concluded by saying that the existence of high thermal conductive nanoparticles increase the thermal conductivity of the nanofluids and causes heat transfer enrichment.

\subsection{Presence of nanoparticles on analysis of heat transfer efficiency}

Table 6 displays the numerical values of average heat transfer rate $(\overline{N u})$ on the rectotrapezoidal uniform heated bottom wall and the cold upright and slanting wall for chosen values of

Rayleigh number and for volume fraction $\varphi=0.00$. If we compare the numerical values with Table 3 or 4 it is quite clear that the numerical values are much lesser than either volume fraction of $\varphi=0.05$ or 0.1 .

Table 6. Average Nusselt number $\overline{N u}$ vs Ra for bottom wall and left cold wall for volume fraction $\varphi=0.00$ (pure fluid) and for $\varphi=0.05$ and 0.1

\begin{tabular}{|c|c|c|c|c|c|c|c|}
\hline SL & Ra & $\begin{array}{c}\text { Bottom } \\
\text { wall } \\
\boldsymbol{\varphi = 0}\end{array}$ & $\begin{array}{c}\text { Left cold } \\
\text { wall } \\
\boldsymbol{\varphi = 0}\end{array}$ & $\begin{array}{c}\text { Enhancement } \\
\text { /bottom wall } \\
\boldsymbol{\varphi}=\mathbf{0 . 0 5}\end{array}$ & $\begin{array}{c}\text { Enhancement /bottom } \\
\text { wall }(\boldsymbol{\varphi}=\mathbf{0 . 1})\end{array}$ & $\begin{array}{c}\text { Enhancement } \\
\text { /left cold wall } \\
\text { wall } \boldsymbol{\varphi = 0 . 0 5}\end{array}$ & $\begin{array}{c}\text { Enhancement /left cold } \\
\text { wall wall } \boldsymbol{\varphi = 0 . 1}\end{array}$ \\
\hline 1 & $10^{3}$ & 7.46 & 3.73 & 15.62 & 33.11 & 15.65 & 32.98 \\
\hline 2 & $10^{4}$ & 8.25 & 4.13 & 11.52 & 24.61 & 11.47 & 24.45 \\
\hline 3 & $10^{5}$ & 11.4 & 5.73 & 10.46 & 21.68 & 10.51 & 21.64 \\
\hline 4 & $10^{6}$ & 16.7 & 8.34 & 9.81 & 19.65 & 10.22 & 20.14 \\
\hline
\end{tabular}

To ascertain the enrichment of heat transfer comparing the case of $\varphi=0.05$ or 0.1 and that of water (base fluid) case, the increase is defined as

$$
E=\frac{N u(\phi=0.05 / 0.1)-N u(\text { basefluid })}{N u(\text { basefluid })} \times 100 \%
$$


It is pretty clear from Table 6 that the enrichment is more than $30 \%$ at lower Rayleigh numbers $\left(\mathrm{Ra}=10^{3}\right)$ and it is nearly $20 \%$ for higher Rayleigh number of $\left(\mathrm{Ra}=10^{6}\right)$ for the bottom wall as well as for the cold vertical left walls for volume fraction $\varphi=0.1$.

\section{CONCLUSIONS}

The presence of sataurated $\mathrm{Cu}$-water nanofluid in a rectotrapezoidal enclosure having a heated bottom boundary, was studied by natural convection heat transfer method and evaluated by finite element strategy. The prominence of measurable factors such as Rayleigh number and nanoparticle vol. fraction on heat transfer parameters and fluid flow were inspected in details.

The main results of this finite element numerical analysis of rectotrapezoidal enclosure led to the following conclusions.

- Consideration of lesser Rayleigh number $\mathrm{Ra}=10^{4}$, resulted in formation of weak anti-clockwise flow strength and dome shaped isothermal contour in the rectotrapezoidal cavity. Circulation strength of streamlines as observed increase with higher Rayleigh number and and are also found to be increasing in strength with higher volume fraction.

- Consideration of Rayleigh numbers, $\mathrm{Ra}=10^{6}$, resulted in predominant convection heat transfer impact all through the rectotrapezoidal enclosure and this can be revealed from the distorted, twisted isotherms and higher value streamline contour values.

- Development of heat transfer $(\mathrm{Nu})$ in the enclosure is strongly based on volume fraction of nanofluids and is also influenced by the Rayleigh number effects.

- The average heat transfer rate $(\overline{N u})$ showes an increase with introduction of $\mathrm{Cu}$-nanoparticles in comparison to its predecessor with normal base fluid water and it has a great impact as revealed from the numerical values at higher values of Rayleigh number of $\mathrm{Ra}=10^{5}$ and $10^{6}$.

- Heat transfer enhancement occurs by more than $30 \%$ at lower Rayleigh numbers $\left(\mathrm{Ra}=10^{3}\right)$ and it is nearly $20 \%$ for higher Rayleigh number of $\left(\mathrm{Ra}=10^{6}\right)$ for the bottom wall as well as for the cold vertical left walls by addition of $\mathrm{Cu}$-water nanoparticles.

\section{ACKNOWLEDGMENT}

The corresponding author wants to thank IIT Kharagpur, Mechanical Engineering Department, West Bengal India, CFD lab for technical help.

\section{REFERENCES}

[1] Ho CJ, Chen MW, Li ZW, (2008). Numerical simulation of natural convection of nanofluid in a square enclosure: effects due to uncertainties of viscosity and thermal conductivity. International Journal of Heat and Mass Transfer 51(17-18): 4506-4516. https://doi.org/10.1016/j.ijheatmasstransfer.2007.12.019
[2] Bouchoucha AM, Bessaïh R. (2015). Natural convection and entropy generation of nanofluids in a square cavity. International Journal of Heat and Technology 33(4): https://doi.org/10.18280/ijht.330401

[3] Mahmoudi A, Mejri I, Omri A. (2016). Study of natural convection in a square cavity filled with nanofluid and subjected to a magnetic field. International Journal of Heat and Technology 34(1): 73-79. https://doi.org/10.18280/ijht.340111

[4] Ahrara1 AJ, Djavareshkian MH, Ataiyanc M. (2017). Numerical simulation of $\mathrm{Cu}$-water nanofluid magnetohydro-dynamics and heat transfer in a cavity containing a circular cylinder of different size and positions. International Journal of Heat and Technology 35(2): 110. https://doi.org/: 10.18280/ijht.350225

[5] Oztop HF, Abu-Nada E. (2008) Numerical study of natural convection in partially heated rectangular enclosures filled with nanofluids. International Journal of Heat and Fluid Flow 29(5): 1326-1336. https://doi.org/: 10.1016/j.ijheatfluidflow.2008.04.009

[6] Basak T, Roy S, Natarajan E. (2008). Analysis of steady convective heating for molten materials processing within trapezoidal enclosures. Industrial Engineering Chemistry Research 47(22): 8652-8666. https://doi.org/10.1021/ie800263c

[7] Dutta S, Biswas AK. (2018) Entropy generation due to natural convection with non -uniform heating of porous quadrantal enclosure-a numerical study. Frontiers in Heat and Mass Transfer (FHMT) 10(8): 1-12. https://doi.org/10.5098/hmt.10.8

[8] Dutta S, Biswas AK, Pati S. (2018). Natural convection heat transfer and entropy generation inside porous quadrantal enclosure with non isothermal heating at the bottom wall. Numerical Heat Transfer, Part A: Applications 73(4): 222-240. https://doi.org/10.1080/10407782.2018.1423773

[9] Choi SUS. (1995). Enhancing thermal conductivity of fluids with nanoparticles. The Proceedings of ASME International Mechanical Engineering Congress and Exposition, San Francisco, USA Bejan A. Constructal thermodynamics. Constructal Law \& Second Law Conference, Parma, pp. S1-S8.

[10] Yu ZT, Xu X, Hu YC, Fan LW, Cen KF. (2011). Numerical study of transient buoyancy-driven convective heat transfer of water-based nanofluids in a bottom-heated isosceles triangular enclosure. International Journal of Heat and Mass Transfer 54(1-3): 526-532.

https://doi.org/10.1016/j.ijheatmasstransfer.2010.09.017

[11] Khanafer K, Vafai K, Lightstone M. (2003). Buoyancydriven heat transfer enhancement in a two-dimensional enclosure utilizing nanofluids. International Journal of Heat and Mass Transfer 46(19): 3639-3653. https://doi.org/: 10.1016/S0017-9310(03)00156-X

[12] Jou RY, Tzeng SC. (2006). Numerical research of nature convective heat transfer enhancement filled with nanofluids in rectangular enclosures. International Communications in Heat and Mass Transfer 33(6): $727-$ 736.

https://doi.org/10.1016/j.icheatmasstransfer.2006.02.01 6

[13] Choi SUS, Eastman JA. (1995). Enhancing thermal conductivity of fluids with nanoparticles. In: Siginer 
DA, Wang HP. (Eds.). Developments and Applications of Non-Newtonian Flows. ASME, New York, pp. 99105.

[14] Keblinski P, Phillpot SR, Choi SUS, Eastman JA, (2002). Mechanisms of heat flow in suspensions of nano-sized particles (nanofluids). International Journal of Heat and Mass Transfer 45(4): 855-863. https://doi.org/10.1016/S0017-9310(01)00175-2

[15] Mahmoudi AH, Pop I, Shahi M, Talebi F. (2013). MHD natural convection and entropy generation in a trapezoidal enclosure using $\mathrm{Cu}$-water nanofluid. Computers and fluids 72: 46-62. https://doi.org/10.1016/j.compfluid.2012.11.014

[16] Saleh H, Roslan R, Hashim I. (2011). Natural convection heat transfer in a nanofluid-filled trapezoidal enclosure. International Journal of Heat and Mass Transfer 54(1-3): 194-201. https://doi.org/10.1016/j.ijheatmasstransfer.2010.09.053

[17] Esfe MH, Arani AA, Yan WM, Ehteram H, Aghaie A, Afrand M. (2016). Natural convection in a trapezoidal enclosure filled with carbon nanotube-EG-water nanofluid. International Journal of Heat and Mass Transfer 92: 76-82. https://doi.org/10.1016/j.ijheatmasstransfer.2015.08.036

[18] Nayak RK, Bhattacharyya S, Pop I. (2018). Effects of nanoparticles dispersion on the mixed convection of a nanofluid in a skewed enclosure. International Journal of Heat and Mass Transfer 125: 908-919. https://doi.org/10.1016/j.ijheatmasstransfer.2018.04.088

[19] Sharma B, Kumar S, Paswan MK. (2018). Analytical solution for mixed convection and MHD flow of electrically conducting non-Newtonian nanofluid with different nanoparticles: A comparative study. International Journal of Heat and Technology 36(3): 987-996. https://doi.org/10.18280/ijht.360327

[20] Dutta S, Biswas AK, (2018). Mixedconvection analysis of copper-water nanofluids in a rectotrapezoidal enclosure. Proceedings of the 7th International and 45th National Conference on Fluid Mechanics and Fluid Power (FMFP), IIT Bombay, Mumbai, India, pp. 1-4.

[21] Xuan Y, Roetzel W. (2000). Conceptions for heat transfer correlation of nanofluids. International Journal of Heat and Mass Transfer 43(19): 3701-3707. https://doi.org/10.1016/S0017-9310(99)00369-5

[22] Wen DS, Ding YL. (2004). Experimental investigation into convective heat transfer of nanofluids at entrance area under laminar flow region. International Journal of Heat and Mass Transfer 47(24): 5181-5188. https://doi.org/10.1016/j.ijheatmasstransfer.2004.07.012

[23] Brinkman HC. (1952). The viscosity of concentrated suspensions and solution. The Journal of Chemical
Physics

20(4):

$571-581$

https://doi.org/10.1063/1.1700493.(2004)

[24] Zienkiewicz OC, Taylor RL. (1991). The finite element Method. 4th ed. McGraw-Hill.

[25] Abu-Nada E, Oztop HF. (2009). Effects of inclination angle on natural convection in enclosures filled with $\mathrm{Cu}-$ water nanofluid. International Journal of Heat and $\begin{array}{llll}\text { Fluid } & \text { Flow } & \text { 669-678. }\end{array}$ https://doi.org/10.1016/j.ijheatfluidflow.2009.02.001

\section{NOMENCLATURE}

$c_{p} \quad$ specific heat of the fluid, $\mathrm{Jkg}^{-1} \mathrm{~K}^{-1}$

g accleration due to gravity, $\mathrm{ms}^{-2}$

$\mathrm{h}$ convective heat transfer coefficient, $\mathrm{Wm}^{-2} \mathrm{~K}^{-1}$

$\mathrm{k}$ thermal conductivity, $\mathrm{Wm}^{-1} \mathrm{~K}^{-1}$

$\mathrm{L}$ enclosure length, $\mathrm{m}$

$\mathrm{Nu}$ local Heat transfer coefficient, (Nusselt number)

$\overline{\mathrm{Nu}}$ Average heat transfer coefficient, (avg. Nu)

$\mathrm{p}$ pressure, $\mathrm{Nm}^{-2}$

$\mathrm{P} \quad$ non-dimensionless pressure

Pr Prandtl Number(dimensionless)

$\mathrm{T}$ temperature, $\mathrm{K}$

$\mathrm{u}, \mathrm{v} \quad \mathrm{x}, \mathrm{y}$ velocity components, $\mathrm{ms}^{-1}$

$\mathrm{U}, \mathrm{V}$ x, y velocity components (dimensionless)

$\mathrm{x}, \mathrm{y}$ axial and transverse co ordinates, $\mathrm{m}$

\section{Greek symbols}

$\alpha \quad$ thermal diffusivity

$\beta \quad$ thermal expansion coefficient

$\varphi \quad$ volume fraction

$\theta \quad$ dimensionless temperature

$\mu \quad$ dynamic viscosity

$v \quad$ kinematic viscocity

$\rho \quad$ density of fluid

$\phi \quad$ inclination angle of RT enclosure

$\phi_{\mathrm{t}} \quad$ transport variable

\section{Subscripts}

avg. average

b, c bottom wall, cold wall

$\mathrm{f}_{\mathrm{w}} \quad$ base fluid (water)

nf nano fluid

$\mathrm{p}_{\mathrm{n}}$ particle (nano-cu)

$\mathrm{min} / \mathrm{max}$ minimum maximum

RT Rectotrapezoidal

Vs. Versus 